\title{
Using evaluation techniques and performance claims to demonstrate public relations impact: An Australian perspective
}

\author{
Robina Xavier $^{\mathrm{a}, *}$, Kim Johnston ${ }^{\mathrm{a}}$, Amisha Patel ${ }^{\mathrm{a}}$, \\ Tom Watson ${ }^{b}$, Peter Simmons ${ }^{b}$ \\ ${ }^{a}$ School of Advertising, Marketing and Public Relations, Queensland University of Technology, Brisbane, Australia \\ ${ }^{\mathrm{b}}$ School of Communication, Charles Sturt University, Bathurst, Australia
}

Received 16 December 2004; received in revised form 15 April 2005; accepted 3 May 2005

\begin{abstract}
Public relations professionals use many methods to demonstrate their contribution to organizational goals, yet it is unclear how their attitudes towards evaluation and the reporting of success matches real outcomes. Ten years after the International Public Relations Association produced an evaluation gold paper, this study combines research on Australian practitioners' evaluation practices and attitudes, and data from industry awards to identify how practitioners demonstrate their accountability. Data suggest that despite the attention paid to evaluation by the academy and industry, practitioners still focus on measuring outputs, not outcomes to demonstrate performance and continue to rely heavily on media-based evaluation methods.
\end{abstract}

(C) 2005 Elsevier Inc. All rights reserved.

Keywords: Evaluation; Measurement; Practitioners; Public relations

\section{Introduction}

Public relations program evaluation plays a significant role in demonstrating accountability and effectiveness (Dozier, 1990; Fairchild, 2002), and organizational impact (Radford \& Goldstein, 2002). As there is no method for measuring effectiveness, practitioners select among an array of different methods and models to demonstrate their effectiveness. Evaluation models can be categorized into those focusing

\footnotetext{
* Corresponding author. Tel.: +61 73864 2645; fax: +61 738641811.

E-mail address: r.xavier@qut.edu.au (R. Xavier).
} 
on a specific process of public relations such as Noble's (1999) dimensional model of media evaluation, or those accommodating an integrated planning approach such as Cutlip, Center, and Broom's (2000) preparation, implementation and impact model, Lindenmann's (1993) three-step public relations yardstick and Watson's (2001) short term and continuing models of evaluation to respond to effects created by a public relations program.

While Center and Jackson (2003) consider that measurement and evaluation have emerged as central to effective practice, the reporting of public relations success measures against actual achievement is unclear. Research into practitioner attitudes and evaluation practice consistently reflects an opinion that evaluation is essential to practice but is still talked about more than practised (Gregory, 2001; Judd, 1990).

Whereas Center and Jackson (2003) suggest there is an increasing emphasis on measuring program outcomes in terms of impact on publics, a number of studies have established that generally evaluation is restricted to program output (Gregory, 2001; Pohl \& Vandeventer, 2001;Walker, 1994; Watson, 1997). Cutlip et al. (2000) note that this focus on outputs may be due to the convenience and accessibility of data to inform such evaluation.

Research into practitioner evaluation usage also reveals that no one country practises evaluation more than another (IPRA, 1994). Pieczka (2000) studied entries in the United Kingdom's Sword of Excellence awards spanning 13 years from 1984, and found no clear relationship between stated objectives and evaluation. In Canada, Piekos and Einsiedel (1990) found scientific research methods were seldom used for impact evaluation and similar results were reported by Dozier (1990) who found that the more scientific the style, the less frequently it is used.

Two 1993 surveys of Australian practitioners found a substantial gulf between practitioner attitudes and practice. Walker (1997) reported that although most practitioners agreed that research was an accepted part of public relations planning, only $55 \%$ of practitioners reported very frequently or occasionally evaluating the impact of their programs. Half of the practitioners surveyed did not believe that they could precisely measure public relations effectiveness (Walker, 1997).

(RQ1) What methods of evaluation are Australian practitioners using to demonstrate performance?

Australian studies (Macnamara, 2002; Walker, 1994, 1997) found that while practitioners used a mix of evaluative measures, there was a focus on media coverage that lacked any sound analysis, and no related measures to validate program effectiveness were provided. Gregory (2001) and Pieczka (2000) suggest such reliance may stem from the value practitioners place on the tangible evidence of achievement provided by media.

(RQ2) How is media coverage positioned as an evaluation tool within Australian public relations campaigns?

In 1994, the International Public Relations Association (IPRA), in conjunction with the Public Relations Institute of Australia (PRIA) and Public Relations Institute of South Africa (PRISA), produced a gold paper on public relations evaluation, stressing the need for professionals to demonstrate their accountability through evaluation (IPRA, 1994). A decade on, evaluation and accountability are recognised as a strong part of good practice, however, research suggests that practitioners still have limited understanding of the use of evaluation research or restrict its use to particular types (Phillips, 2001; Watson, 2001). Pohl and Vandeventer (2001) found less than half of the respondents identified formal evaluation methods in their campaign plans. 
Given the international interest in evaluation practice, this study sought to map contemporary Australian practice and consider whether evaluation practice has been enhanced in recent years.

(RQ3) Has the use of evaluation methods in Australian public relations campaigns changed during the period 1997-2001?

\section{Methodology}

Major studies of evaluation practice have used professional bodies to reach a practitioner sample (see, for example, Dozier, 1985, 1988 with the PRSA and IABC and Watson, 1994, 1996 with the IPR), and used targeted samples of practitioners in prominent organisations (see, for example, Lindenmann, 1990; Walker, 1997). Other studies have sought insight by reviewing entries for industry awards (Blissland, 1990; Gregory, 2001; Pieczka, 2000; Walker, 1994).

Informed by this research tradition, this study used a two-step research methodology. Firstly, Australian award-winning public relations cases were analysed against academic planning frameworks for evaluation. While this study focuses exclusively on Australian practice, Australian public relations campaigns have been recognised internationally for best practice, winning awards in the International Association of Business Communicators Golden Quill Awards and the IPRA Golden Globe Awards. Secondly, public relations practitioners were surveyed to elicit their views on evaluation practice and to identify key drivers and barriers for evaluation practices.

For the analysis of public relations cases, a coding instrument was drawn principally from IPRA's gold paper on evaluation (1994), which divides evaluation into three categories: input, output, and outcome. This categorisation of evaluation methods was developed by IPRA and the PRIA after consideration of a wide range of available models. As trends in input evaluation within Australian public relations cases have been reported elsewhere (Xavier, Johnston, \& Patel, 2003), this paper focuses on in-progress and post-campaign evaluation practices as represented by output and outcome evaluation methods.

The second step involved the administration of a survey of Australian practitioners, based on Watson's (1996) study of UK practitioners. After completing a series of questions posed on a Likert scale, respondents were asked: Is there anything you would like to add about public relations evaluation and research? This study analyses responses to this question. Findings from the quantitative analysis of practitioner attitudes have been reported elsewhere (Watson \& Simmons, 2004).

\section{Sample}

The sample for this research is taken first from 118 award-winning entries to the PRIA Golden Target Awards, from 1997 to 2001. Entries are judged by a panel of senior public relations practitioners and academics against criteria set by the PRIA. The specific unit of observation for this study was the results and evaluation sections of each award. The anonymous practitioner survey was distributed by the PRIA, which also endorsed the study. An email with a web link to the questionnaire was sent to approximately 2800 PRIA member email addresses in late 2003. Further, 100 members of the Local Government Public Relations Association of Australia were also emailed the survey. Of the 216 completed surveys received, 74 participants responded to the open-ended question on evaluation. 


\section{Data analysis and coding}

The awards data were coded by two coders against output/outcome categories and methods. Prior to data collection, the research instrument was tested by both coders on three cases. Coding categories and operational definitions were refined and retested on three further cases, resulting in a reliability score of 0.90 for the instrument. During the coding process, reliability was checked periodically and remained above this level and was checked again at the completion of coding.

Data from the cases were entered into Statistical Package for the Social Sciences (SPSS). Frequency counts and descriptive statistics were calculated for the relevant variables with chi-square analyses and ANOVA conducted where appropriate. The open-ended comments elicited through the practitioner survey were reviewed and emerging themes of barriers to evaluation, media evaluation practices, and practitioner suggestions for evaluation identified. The comments were then coded against these themes.

\section{Limitations}

The sample includes only those cases that were entered into the PRIA's awards, thereby representing a limited percentage of Australian public relations campaigns. Entry is open only to PRIA members, therefore this study does not map the practices of non-PRIA members who represent a significant part of the Australian industry. The sample also includes only award-winning cases, thus relying on the original judges' understanding and application of criteria.

Walker (1994) set a precedent for using this sample in reporting evaluation trends in Australian public relations and similar data sets have been used internationally (Blissland, 1990; Pieczka, 2000). Distribution of the survey was limited to the members of two industry organisations and thus, is not generalizable to the entire population of Australian practitioners. As participation was voluntary, it is arguable that those with strong views on the topic were more likely to respond.

\section{Results}

\subsection{Overall use of evaluation methods}

All campaigns used evaluation methods in some manner. Output evaluation was used in 106 campaigns $(N=118)$, and outcome evaluation was used in 80 campaigns $(N=118)$. Overall, output evaluation methods accounted for $74 \%$ of reported methods across the sample with outcome evaluation methods representing 26\%. Practitioners used an average of three evaluation methods $(M=3.14$, S.D. $=1.56)$ per campaign, which comprised two output evaluation methods $(M=2.31$, S.D. $=1.48)$ and one outcome method $(M=1.00$, S.D. $=0.92)$. The maximum number of output and outcome evaluation methods used per campaign were six and four, respectively.

The most common output evaluation methods were response rates $(66.10 \%)$, which included measures such as attendance to meetings or call centre feedback, followed closely by media monitoring $(64.41 \%)$ and media content analysis $(41.53 \%$ ) (see Table 1$)$. The least common output evaluation methods were organizational culture studies $(0.85 \%)$ and communication audits $(1.69 \%)$.

The most common outcome evaluation methods were activity outcome (29.66\%), used to measure the result of a program aimed at a particular target such as adding value to a share price, achieving change 
Table 1

Use of output and outcome evaluation methods in campaigns

\begin{tabular}{llll}
\hline Output evaluation methods & Percent use & Outcome evaluation methods & Percent use \\
\hline Response rates & 66.10 & Activity outcome & 29.66 \\
Media monitoring & 64.41 & Surveys & 22.88 \\
Media content analysis & 41.53 & Unobtrusive data collection & 17.80 \\
Distribution statistics & 28.81 & Focus groups & 4.24 \\
Coding material & 8.47 & In-depth interviews & 4.24 \\
Statistical analysis & 6.78 & Pre- and post-tests & 3.39 \\
Attitude and image studies & 5.93 & Quasi-experimental study & 0.00 \\
Audience analysis & 4.24 & & \\
Complaint analysis & 2.54 & & \\
Communication audit & 1.69 & & \\
Organizational culture study & 0.85 & & \\
\hline
\end{tabular}

in policies or legislation, and surveys $(22.88 \%$ ) used to confirm change in target publics (see Table 1). The least common outcome evaluation methods were pre- and post-tests (3.39\%) and in-depth interviews (4.24\%), with no record of quasi-experimental studies.

The practitioner survey provided insight as to how practitioners selected evaluation measures, their personal disposition and nomination of barriers to evaluation that included time, budget, training and client understanding of evaluation.

Currently there is very little PR research/evaluation undertaken due to limited budgets, time and lack of know-how.

More often than not, clients and practitioners desires for evaluation are outweighed by budgetary restraints. It is still better to do something than nothing even if it isn't as effective as it could be.

In noting the importance of evaluation to the industry's credibility, several participants called for the development of new evaluation tools to assist practitioners to develop more sophisticated evaluation methods.

The establishment of a standard evaluation method for PR would be of immense benefit both to the practitioner, the client and more importantly the PR industry as a whole, which suffers due to under-developed and unclear practices.

We have developed our own proprietary measurement tool out of frustration with the lack of acceptable tools in the industry.

\subsection{Use of media evaluation}

While the awards data show a strong practitioner preference for media evaluation, the sophistication of such evaluation varied within the sample. Media evaluation comprised two evaluation methods: media monitoring and media content analysis. Media monitoring calculated the amount of media coverage achieved by monitoring press clippings and calculating supposed audience exposure (IPRA, 1994). Media 
content analysis involved the systematic analysis of clippings to assess the reporting of an organisation's key messages (IPRA, 1994). Media monitoring was used to evaluate performance in $64 \%$ of campaigns $\left(\chi^{2}(1, N=118)=9.80, p<.01\right)$ and media content analysis was used in $42 \%$ of campaigns, however, there was no significant trend in the use or non-use of media content analysis $\left(\chi^{2}(1, N=118)=3.39\right.$, n.s.).

The survey responses confirmed a practitioner focus on media-based evaluation tools. Respondents suggested the pressure for this evaluation type was coming from clients who saw it as a tangible way to understand the public relations process or were seeking some form of standardized approach to evaluation that was easily understood.

Evaluation effectiveness more often than not comes down to what the client wants. I was recently in the US for a PR conference and heard the PR manager for one of the largest tech firms in the world get up and say he doesn't care about quality of message or share of voice. He measures one thing only_number of clips. And it doesn't matter where they have come from. Having a discussion about key message pull-through or quality of audience would have been a waste of time.

\subsection{Changes in evaluation practice}

Based on data gathered approximately 10 years ago, Walker (1997) reported that $96 \%$ of respondents believed 'that public relations research, measurement and evaluation projects will almost certainly grow in importance during the 1990s' (p. 108). However, this study suggests there has been limited change in practitioner focus over the sample period, 1997-2001. To identify whether practitioner use of particular methods was changing over time, we considered the frequency of output and outcome evaluation methods per case and within the overall sample on a yearly basis (see Table 2).

A one-way analysis of variance (ANOVA) indicated that the frequency of output evaluation methods used in each case did not differ significantly by year $(F(4,113)=.886$, M.S.E. $=2.209, p=.475)$. However, the use of outcome evaluation methods per case did show some significant differences over time $(F(4,113)=11.222$, M.S.E. $=0.633, p<.0001)$. While post hoc Bonferroni $t$-tests showed that there was a significant difference in the frequency of usage of outcome evaluation between certain periods and

Table 2

Output and outcome evaluation frequency trends across time

\begin{tabular}{|c|c|c|c|c|c|c|c|c|}
\hline \multirow[t]{2}{*}{ Year } & \multirow[t]{2}{*}{$\begin{array}{l}\text { Number } \\
\text { of cases }\end{array}$} & \multicolumn{2}{|c|}{$\begin{array}{l}\text { Frequency of } \\
\text { output evaluation } \\
\text { methods per case }\end{array}$} & \multicolumn{2}{|c|}{$\begin{array}{l}\text { Frequency of } \\
\text { outcome evaluation } \\
\text { methods per case }\end{array}$} & \multirow[t]{2}{*}{$\begin{array}{l}\text { Total number of } \\
\text { evaluation methods } \\
\text { across all cases }\end{array}$} & \multirow[t]{2}{*}{$\begin{array}{l}\text { Percent of output } \\
\text { evaluation methods } \\
\text { across all cases }\end{array}$} & \multirow[t]{2}{*}{$\begin{array}{l}\text { Percent of outcome } \\
\text { evaluation methods } \\
\text { across all cases }\end{array}$} \\
\hline & & Mean & S.D. & Mean & S.D. & & & \\
\hline 1997 & 22 & 2.14 & 1.283 & 1.14 & 0.774 & 66 & 71.21 & 28.79 \\
\hline 1998 & 18 & 2.17 & 1.724 & 1.06 & 0.873 & 52 & 75.00 & 25.00 \\
\hline 1999 & 22 & 2.27 & 1.386 & 0.50 & 0.512 & 61 & 81.97 & 18.03 \\
\hline 2000 & 27 & 2.78 & 1.311 & 0.48 & 0.580 & 87 & 86.21 & 13.79 \\
\hline 2001 & 29 & 2.14 & 1.684 & 1.75 & 1.066 & 104 & 59.62 & 40.38 \\
\hline Total & 118 & 2.31 & 1.483 & 1.00 & 0.925 & 370 & & \\
\hline
\end{tabular}


the use of outcome evaluation methods was highest in 2001, there was no overall trend towards greater use.

\section{Discussion and implications}

Given the prominence of evaluation methods in public relations texts, the exhortation to enhanced evaluation by industry bodies, and the predictions by Australian practitioners of a stronger focus on evaluation (Walker, 1994), it was expected that some evidence of improvement in practice would be found across the timeframe of this study. However, close to a decade after Walker's (1997) first study of Australian practitioners, there appears to be limited evidence of improvement. While evaluation is clearly evident in campaign planning and reporting, the use of evaluation techniques remains limited to particular types that do not demonstrate true impact on publics or contributions to organizational goals.

There was no evidence of a sustained increase in the number of evaluation methods being used within each campaign over the timeframe, nor any trend towards the higher level outcome category of evaluation methods. In two of the five years representing the middle point of the study's timeframe, the frequency of outcome measures per campaign dropped significantly. While output measures dominated consistently across the five-year period, it is difficult to see how the use of even these measures demonstrate improvement in practice with more than $60 \%$ of cases reported in the final year of the study still using three or less methods to evaluate a campaign. Given the strong positioning of media monitoring as at least one of these techniques, considerable claims of campaign effectiveness are being made from the other methods.

Walker (1997) identified media monitoring as the most frequent evaluation technique of Australian practitioners. While not the most frequent technique found in this study, media evaluation remained one of the most popular choices for practitioners across the five-year timeframe. Walker's earlier study (1994) also suggested that media evaluation focused on counting clips rather than analysis of the coverage. This study confirms those findings, with less than half the award-winning cases including any media content analysis and only two-thirds of those that included media monitoring also addressing media content analysis. Although Noble (1999) suggests practitioners can make cautious links between media evaluation and campaign results, the findings of this study suggest that such caution is not being heeded by Australian practitioners.

Practitioner views on evaluation appear to be driven by a lack of knowledge and skills, time, and confidence illustrated by an inability to make a case for evaluation budgets with their clients or managers, and the frustration at decision-makers' misunderstanding of public relations. Given the prevalence in practitioner comments of the needs and demands of such decision-makers, the voices of organizational managers and clients should be mapped in further research to understand their expectations of public relations outcomes and how they expect practitioners to demonstrate their effectiveness.

The inability of public relations practitioners to demonstrate such effectiveness in line with other management functions leaves the discipline open to cannibalization by other more quantitatively focused sectors. Therefore, initiatives to enhance evaluation practice need to be given priority by industry bodies and education facilities. Such initiatives could focus on practitioner education in specific research techniques (particularly non-media-based techniques) and their applicability in demonstrating different types of performance measures.

Finally, the wide distribution of exemplars of practice, demonstrating innovative and accurate applications of program evaluation, will fortify the profession's ability to make a difference. 


\section{References}

Blissland, J. (1990). Accountability gap: Evaluation practices show improvement. Public Relations Review, 16(2), $25-33$.

Center, A., \& Jackson, P. (2003). Public relations practices (6th ed.). New Jersey: Prentice Hall.

Cutlip, S., Center, A., \& Broom, G. (2000). Effective public relations (8th ed.). New Jersey: Prentice Hall.

Dozier, D. M. (1985). Planning and evaluation in pr practice. Public Relations Review, 11(2), 17-26.

Dozier, D. M. (1988). Organic structure and managerial environment sensitivity as predictors of practitioner membership of the dominant coalition. Paper presented at the Public Relations Division, Association for Educators in Journalism and Mass Communications Conference, Portland, Oregon.

Dozier, D. M. (1990). The innovation of research in public relations practice: Review of a program of studies. Public Relations Research Annual, 2, 3-28.

Fairchild, M. (2002). Evaluation: An opportunity to raise the standing of pr. Journal of Communication Management, 6(4), 305-307.

Gregory, A. (2001). Public relations and evaluation: Does the reality match the rhetoric? Journal of Marketing Communications, 7(3), 171-189.

International Public Relations Association. (1994). Public relations evaluation: Professional accountability. Geneva: IPRA.

Judd, L. R. (1990). Importance and use of formal research and evaluation. Public Relations Review, 16(4), 17-28.

Lindenmann, W. (1990). Research, evaluation and measurement: A national perspective. Public Relations Review, 16 (2), 3-17.

Lindenmann, W. (1993). An 'effectiveness yardstick' to measure public relations success. Public Relations Quarterly, 38, 7-10.

Macnamara, J. (2002). Research and evaluation. In C. Tymson, P. Lazar, \& R. Lazar (Eds.), The new Australian and New Zealand public relations manual (pp. 100-135). Sydney: Tymson Communications.

Noble, P. (1999). Towards an inclusive evaluation methodology. Corporate Communications, 4(1), 14-23.

Phillips, D. (2001). The public relations evaluationists. Corporate Communications, 6(4), 225-237.

Pieczka, M. (2000). Objectives and evaluation in public relations work: What do they tell us about expertise and professionalism? Journal of Public Relations Research, 12(3), 211-233.

Piekos, J., \& Einsiedel, E. (1990). Roles and program evaluation techniques among Canadian public relations practitioners. Public Relations Research Annual, 2, 95-113.

Pohl, G., \& Vandeventer, D. (2001). The workplace, undergraduate education and career preparation. In R. L. Heath (Ed.), Handbook of public relations (pp. 357-368). CA: Sage Publications.

Radford, G. P., \& Goldstein, S. Z. (2002). The role of research methods in corporate communication. Corporate Communications, 7(4), 252-256.

Walker, G. (1994). Communicating public relations research. Journal of Public Relations Research, 6(3), $141-161$.

Walker, G. (1997). Public relations practitioners' use of research, measurement and evaluation. Australian Journal of Communication, 24(2), 97-113.

Watson, T. (1994, July). Public relations evaluation: Nationwide survey of practice in the United Kingdom. Paper presented at the International Public Relations Research Symposium, Bled, Slovenia.

Watson, T. (1996). Public relations evaluation: The second nationwide survey of practice in the United Kingdom. Unpublished manuscript, Winchester, UK.

Watson, T. (1997). Measuring the success rate: Evaluating the PR process and PR programmes. In P. J. Kitchen (Ed.), Public relations: Principles and practices (pp. 283-299). Boston: International Thomson Business Press.

Watson, T. (2001). Integrated planning and evaluation. In R. L. Heath (Ed.), Handbook of public relations (pp. 259-268). Ca: Sage Publications.

Watson, T., \& Simmons, P. (2004). Public relations evaluation-Survey of Australian practitioners. Paper presented at the Australian and New Zealand Communication Association Conference, University of Sydney, Sydney, Australia.

Xavier, R., Johnston, K., \& Patel, A. (2003). Trends in public relations campaign research: An analysis of research methods used by public relations practitioners in campaign development. Paper presented at the Australian and New Zealand Communication Association Conference, QUT, Brisbane, Australia. 